pastures. I hope further experiments with aeroplanes will be continued. It is a good line to follow up, but there will be many practical difficulties to overcome before aeroplane spraying will be brought to a state of perfection where it will be practical in rough forest areas.

In regand to the wilt disease, from the amount of defoliation of these catalpa trees and the rapid death of the caterpillars, I have a suspicion that some wilt disease was present.

Mr. J. S. Houser. The catalpa sphinx is a rather watery, flabby caterpillar and begins to decay very soon after death. This, I think, explains the reason why the breakdown of the caterpillars was so rapid. I believe it was the spraying that was responsible for their death.

Mr. William MOORE. What was the material you used?

Mr. J. S. Houser. Powdered arsenate of lead.

Mr. H. A. Gossard. I was present at the time this work was conducted, and I would say, regarding the question of wilt, that these caterpillars were not starving at all. There was abundant young foliage on the trees the day the dusting was done. We climbed those trees after the work was done, to the tops of them, and branches were brought down. I really didn't do the climbing but I received some of the branches that were brought down, and the amount of dust that was on them and on everything in the grove made us expect that those fellows would begin to wilt-but not with wilt disease. There wasn't a sign, the day I was there, of any disease with those caterpillars. They were there in abundance and were healthy and were feeding at a great rate. Three days later, Mr. Houser made a report that about ninety-nine per cent. of them was dead.

I think these questions are entirely proper but I don't think anyone who was present and saw the work done, would have any suspicion at all that a bacterial disease attacked those caterpillars. It was something else.

President George A. Dean. The next paper is by Mr. D. M. De Long.

\title{
THE BOOM NOZZLE SYSTEM AND THE TRACTION DUSTER AS FACTORS IN GRAPE LEAF HOPPER CONTROL
}

By D. M. De Long, Ohio State University

The Grape Leaf hopper (Erythroneura comes Say) has been a very serious pest in the Erie-Chautauqua grape area along the southeastern shore of Lake Erie for many years. The attacks of these minute insects during several successive summers may be so inconspicuous that the growers may be inclined to regard the pest as a factor of diminishing importance in grape growing, and they are always hopeful that it will 
gradually disappear as a pest; but frequently the following season will favor the growth and development of vast numbers of hoppers, which the grower is generally unprepared to combat.

During the seasons of 1920 and 1921 the hoppers have caused great damage to hundreds of acres of grapes in this section, and naturally the areas most severely attacked were those closely approximating woodlands. The serious damage caused by these pests can be realized more fully when it is known that foliage severely attacked dried prematurely and curled up before the grapes had ripened. Consequently many growers were refused markets for their grapes in 1920 at the Welch grape juice plant on account of the red appearance and sour flavor of the partially ripened fruit.

Many of the growers with a large acreage of grapes were totally unprepared to spray when the nymphs appeared in great abundance, and the leaves began to turn yellow. One of the most progressive growers stated that he had neither sufficient length of time, nor enough men to spray with the customary trailer nozzles, and that if he attempted to do so other fruits must go unsprayed. Furthermore, a large percentage of the hoppers would become adults by the time the spray could be applied.

For many years attempts to combat the Grape Leaf hopper and Grape Berry moth with the customary "set nozzles" have been made with varying success. In the old type of sprayer the nozzles are so arranged that the halves of two rows are sprayed simultaneously, thereby permitting the hoppers to escape from the row by way of the unsprayed portion, many of them flying to safety before the spray. In this type the nozzles were set horizontally to the vine on vertical rods at either side of the tank. This arrangement of nozzles had a tendency to push the leaves downward instead of exposing and treating the under surface where the hoppers usually feed.

The boom system with the arrangement of nozzles for spraying one row at a time from both sides and above has been previously used but the nozzles in that case were placed horizontally to the vine and machines were being delivered to the growers in that condition in 1921. Furthermore the lower nozzle was two or three feet above the ground when the spray was applied and the nozzles were all set in the same plane. In view of the unsatisfactory results obtained from this type of set nozzle a rearrangement of nozzles was devised which has given very satisfactory results. This arrangement permitted the operator to be seated on the spray tank holding a $\frac{5}{8}$ inch horizontal pipe about seven feet long, connected with the spray tank and extending over the top of the row. From this horizontal piece of pipe a three foot pipe connected by three feet of rubber hose extended vertically almost to the ground on either side of the row at a distance of about three and one-half feet apart. 

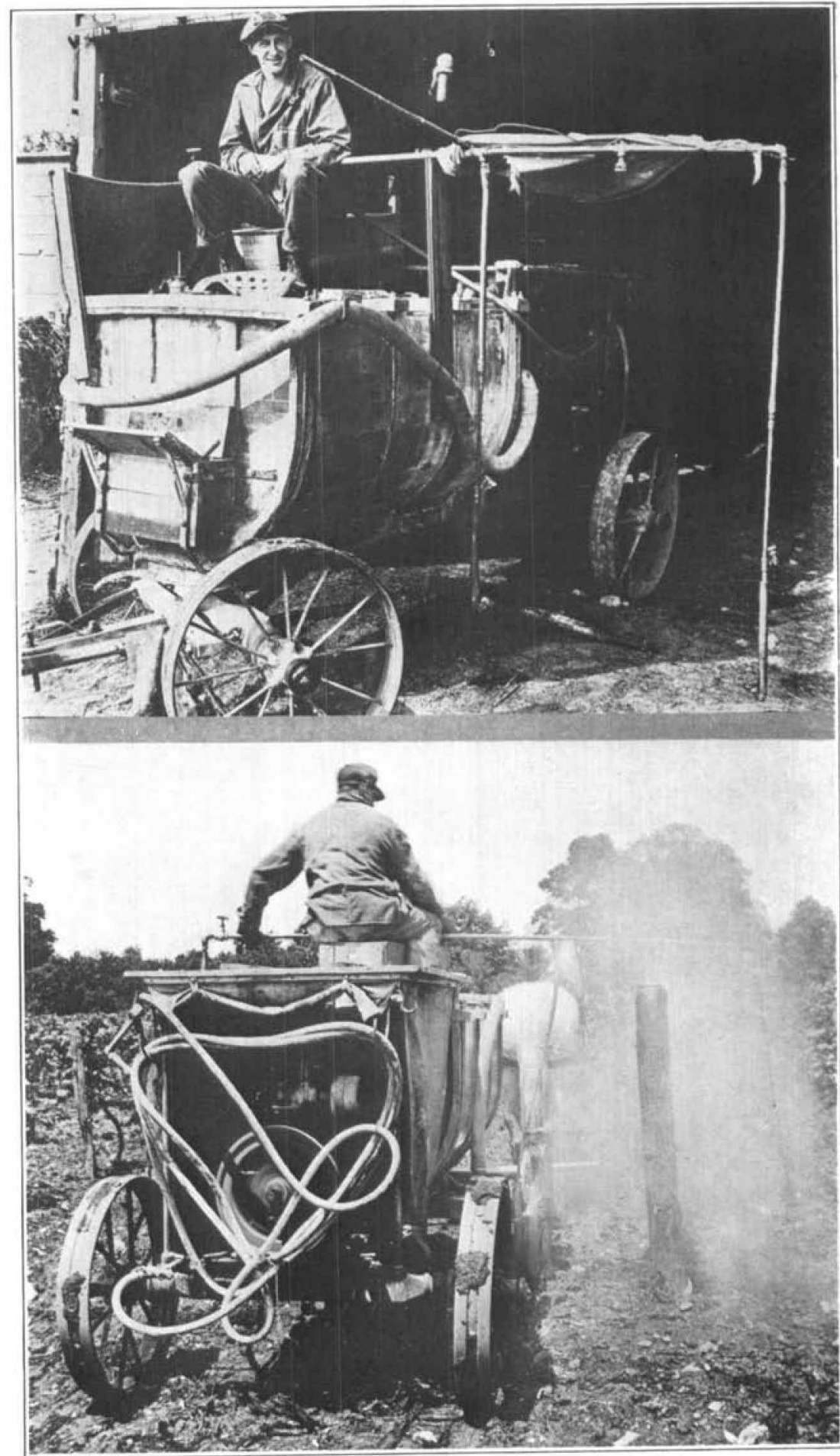

Boom Arraxgement of Set Nozzles

Upper-Showing arrangement of five nozzles for spraying both sides of row simultaneously. Lower-Cloud of spray_enveloping grape row. 
At first seven disk nozzles were used. One was placed so as to point downward from the horizontal pipe, midway between the vertical pipes, and directly over the grape row. Three nozzles were placed on each vertical pipe, one at the extreme lower end pointed upward at an angle of about 45 degrees, another about a foot and one-half above directed upward and slightly backward, and a third about three feet from the bottom directed upward and slightly forward. The nozzles were fitted to the vertical pipe by means of "T's", and an "Ell", which sufficed in the case of the extreme lower one. The principal disadvantage encountered at the start was the spreading of the vertical pipes on the application of pressure from the pump, preventing a thorough application to the foliage. This was readily overcome by a weight at the end of each vertical pipe, and fully as good results were finally obtained in spraying by removing the upper nozzle on each vertical pipe, leaving only five nozzles arranged as described above.

Three things are important in the construction. First, the lower nozzle should be as close to the surface of the ground as possible, as the lower portions are frequently most heavily infested by the nymphs; second, the nozzles should be upturned at an angle of approximately $45^{\circ}$, but this will vary with the vineyard and a difference of $5^{\circ}$ will often cause a 15 to $20 \%$ difference in the killing; third, the lateral nozzles should be alternated slightly forward and backward.

The driving spray from the up-turned nozzles raises the leaves and covers the under surface thoroughly, while the nozzle above the vine covers the upper surface. Under sufficient pressure a perfect mist was obtained by this arrangement of nozzles, and observations of the leaves just after spraying proved that the greater percentage of immature hoppers had been hit and killed by the spray.

In the vineyard where this experiment was carried on, the undersides of the leaves were almost covered with hopper nymphs, and an excellent chance was afforded to try out this apparatus on a large acreage.

Comparing the two types of "set nozzle grape sprayers" the boom system has certain advantages over the old type; first, the thorough treatment of one row at a time, enveloping both sides of the vine in a fine driving mist offering little opportunity for either nymphs or adults to escape to safety; second, the up-turned nozzles lift the leaves and thoroughly cover the under surfaces. As compared with the trailer system the economic factors of time and expense are important. It requires more than twice as long to spray with trailer nozzles than to cover the same area twice with the boom system and an extra man is necessary to operate the trailer nozzles. In other words the extra 5 to $10 \%$ killed by the trailer system costs as much as the first 80 or $85 \%$ which can be obtained by the boom system and is an economic control. 


\section{A Preliminary Report of Dusting for Control ${ }^{1}$}

The traction duster has been used the past season in an attempt to control the grape leaf hopper. A $2 \%$ nicotine dust was used with both Bordeaux and lime. Applications on different plots varied at the rate of from 20 to 75 pounds per acre and it was only at the rate of 60 pounds per acre or more that a decided killing of both adult and nymphal stages was secured. Scarcely a live hopper could be found in some plots and dead leaf hoppers were observed in great abundance under the vines. On other plots treated on the following evening with apparently the same material and the same amount there was only a small per cent of killing. For this reason it is very hard to state what condition caused the killing. The different results obtained may be due entirely to the temperature and humidity conditions and there may have been a difference in the percentage of nicotine in the mixture.

Although a large amount of experimentation will be necessary to determine the conditions of killing, the interesting fact is that an economic control has been obtained by the dust on some plots.

President George A. Dean. The next paper is "Derris as a Promising Insecticide," by R. W. Wells, F. C. Bishopp, and E. W. Laake.

\section{DERRIS AS A PROMISING INSECTICIDE}

By R. W. WELLS, F. C. BISHOPP and E. W. LAAKE, United States Bureau of Entomology

There is a distinct demand for an insecticide for use on domestic animals which can be applied in the dry or dust form and be depended upon to give satisfactory control. This is especially true in regard to the control of lice on live stock. The various species of lice seldom become sufficiently numerous to be of marked importance as parasites, except during the winter when the conditions are least favorable for the application of liquids. In an effort to meet this need the authors and their associates have tested a considerable number of dry insecticides under varying conditions and against various external parasites. Among the substances tested was powdered derris. The insecticidal properties of this material were brought to the attention of American entomologists by Messrs. N. E. McIndoo, A. F. Sievers, and W. S. Abbott. ${ }^{3}$ As shown by these authors this material has some promise both as a contact and as a stomach poison for insects.

${ }^{1}$ All materials used in the trial were furnished by the Niag ara Sprayer Co. through the kindness of Mr. F. J. Sutton.

2Published by permission of the Chief of the Bureau of Entomology.

${ }^{3}$ Derris as an insecticide, Journal of Agr. Research, vol. 17, No 5, pp. 177-200, August 15, 1919. 